Prof Eric Bateman has served on advisory boards for Boehringer Ingelheim, AstraZeneca, Elevation Pharma, Napp Pharma, Novartis, Almirall, Forest, and Merck and Takeda; has served as a consultant to Navigant Consulting, IMS consulting group, ALK-Abello, Almirall, Hoffman la Roche, and ICON; has been paid lecture fees by AstraZeneca, ALK-Abello, Chiesi, Boehringer Ingelheim, GlaxoSmithKline, Nycomed/Takeda, Novartis, Pfizer, and Indegene Lifesciences Ltd.

Prof Shu Hashimoto has no conflicts of interest.

\section{P194 ONCE-DAILY OVA149 PROVIDES SUPERIOR BRONCHODILATION AND IMPROVES LUNG FUNCTION VERSUS TWICE-DAILY FLUTICASONE/SALMETEROL IN COPD PATIENTS: THE ILLUMINATE STUDY}

doi:10.1136/thoraxjnl-2012-202678.255

${ }^{1} \mathrm{C}$ Vogelmeier, ${ }^{2 E}$ Bateman, ${ }^{3} \mathrm{~J}$ Pallante, H Bryant ${ }^{4},{ }^{3} \mathrm{~V}$ Alagappan, ${ }^{3} \mathrm{P}$ D'Andrea, ${ }^{3} \mathrm{E} \mathrm{He}$, ${ }^{3} \mathrm{D}$ Banerji. 'Department for Respiratory Diseases, University of Marburg, Marburg, Germany: ${ }^{2}$ Department of Medicine, University of Cape Town, Cape Town, South Africa; ${ }^{3}$ Novartis Pharmaceuticals Corporation, East Hanover, NJ, USA; ${ }^{4}$ Novartis Horsham Research Centre, Horsham, West Sussex, UK

Introduction QVA149 is a novel inhaled once-daily dual bronchodilator containing a fixed-dose combination of the long-acting $\beta_{2}$-agonist (LABA) indacaterol and the long-acting muscarinic antagonist (LAMA) glycopyrronium, in development for the maintenance treatment of COPD. This study evaluated the superiority of OVA149 once daily in terms of efficacy over fluticasone/ salmeterol twice daily in patients with COPD.

Methods In this 26 week, multicentre, double-blind, doubledummy, parallel-group study patients aged $\geq 40$ years with moderate-to-severe COPD (post-bronchodilator $\mathrm{FEV}_{1} / \mathrm{FVC}<0.7$ and $\mathrm{FEV}_{1}$ $\geq 40 \%$ to $<80 \%$ predicted), no history of exacerbations in the previous year and smoking history $\geq 10$ pack-years, were randomised (1:1) to receive QVA149 110/50 $\mu$ g (via the Breezhaler ${ }^{\circledR}$ device) or fluticasone/salmeterol 500/50 $\mu$ g (via the Accuhaler ${ }^{\circledR}$ device). The primary efficacy end point was standardised $\mathrm{FEV}_{1}$ area under the curve $\left(\mathrm{FEV}_{1} \mathrm{AUC}_{0-12 \mathrm{~h}}\right)$ at Week 26. The pre-dose trough $\mathrm{FEV}_{1}$ on Week 12 and 26 and peak FEV ${ }_{1}$ on Day 1, Week 12 and Week 26 were also measured.

Results A total of 523 patients (35.1\% on inhaled corticosteroids use) were randomised [QVA149, $\mathrm{n}=259$; fluticasone/salmeterol, $\mathrm{n}=264$; male $(70.9 \%)$; mean age: 63.3 years; mean post-bronchodilator $\mathrm{FEV}_{1}$ : $60.2 \%$ predicted], $82.6 \%$ completed. $\mathrm{FEV}_{1} \mathrm{AUC}_{0-12 \mathrm{~h}}$ was found clinically meaningful and statistically significant in favour of OVA149 compared to fluticasone/salmeterol on Day 1, Week 12 and Week 26 (Least squares mean [LSM] treatment difference $=70 \mathrm{~mL}$, $120 \mathrm{~mL}, 140 \mathrm{~mL}$, respectively; all $\mathrm{p}<0.001)$. Pre-dose trough $\mathrm{FEV}_{1}$ was significantly $(p<0.001)$ higher for OVA149 compared with fluticasone/salmeterol at Week 12 and 26 (LSM treatment difference $=90 \mathrm{~mL}$ and $100 \mathrm{~mL}$, respectively; $p<0.001)$. The LSM treatment difference for peak $\mathrm{FEV}_{1}$ was also statistically significant for QVA149 compared with fluticasone/salmeterol on Day 1 $(70 \mathrm{~mL})$, Week $12(150 \mathrm{~mL})$ and Week $26(150 \mathrm{~mL})$, all $\mathrm{p}<0.001$.

Conclusion QVA149 once daily provided superior bronchodilation at all time-points compared to fluticasone/salmeterol twice daily and showed clinically meaningful improvements in lung function for a sustained period of 26 weeks. In moderate-to-severe COPD patients without a history of exacerbations in the previous year, LABA/LAMA dual bronchodilation with once-daily QVA149 proves a superior alternative to twice-daily fluticasone/salmeterol.

Prof Claus Vogelmeier has served on scientific advisory boards for AstraZeneca, Boehringer Ingelheim, Chiesi, GlaxoSmithKline, Janssen, Novartis, Pfizer, Almirall, Takeda, and Sterna Biologicals; has been paid lecture fees by AstraZeneca, Chiesi, GlaxoSmithKline, Janssen, Talecris, Novartis, Boehringer Ingelheim, Takeda, and Pfizer.
Prof Eric Bateman has served on advisory boards for Boehringer Ingelheim, AstraZeneca, Elevation Pharma, Napp Pharma, Novartis, Almirall, Forest, and Merck and Takeda; has served as a consultant to Navigant Consulting, IMS consulting group, ALK-Abello, Almirall, Hoffman la Roche, and ICON; has been paid lecture fees by AstraZeneca, ALK-Abello, Chiesi, Boehringer Ingelheim, GlaxoSmithKline, Nycomed/Takeda, Novartis, Pfizer, and Indegene Lifesciences Ltd.

\section{Lung cancer investigation, treatment and survival}

\section{P195 CASE SERIES: HOW USEFUL ARE FLEISCHNER GUIDELINES FOR NODULE SURVEILLANCE IN A DISTRICT GENERAL HOSPITAL?}

doi:10.1136/thoraxjnl-2012-202678.256

RW Lee, KE Millward, FE Ossai, D Ellis, M Townsend, S Lohani Darent Valley Hospital, Dartford, Kent, United Kingdom

Background Surveillance of pulmonary nodules aims to identify early-stage lung cancers where radical therapy can offer cure. Interval CT scans track nodule characteristics with Fleischner criteria commonly used in an attempt to standardise care. There remains debate regarding the applicability of Fleischner guidance in populations of UK patients that can differ substantially from those included in existing studies that define the Fleischner recommendations.

\section{Objectives}

- Audit compliance of pulmonary nodule follow up with Fleischner Guidelines.

- Compare local outcomes with those used to create Fleischner guidelines.

- Compare local compliance with published compliance.

Methods Patients referred to a specialist respiratory nurse service for pulmonary nodule surveillance since 2008 (including patients already under surveillance) with opportunity for 2 years of completed follow-up were included with retrospective review of the nodule database/electronic records and imaging. Patients were risk stratified according to nodule size and Fleischner risk category (e.g. smoking).

Results 111 patients under surveillance were identified of whom 56 were Male and 55 Female with median age 67 (34-91) years. 67 were solitary and 44 were multiple. Patients were stratified to Lowand High-risk groups according to main nodule size: (L1-4 or H1-4 respectively). Each group included; High-risk: $\mathrm{H} 1(<=4 \mathrm{~mm}) 10, \mathrm{H}_{2}$ (>4-6mm) 25, H3 (>6-8mm) 19 and $\mathrm{H} 4(>8 \mathrm{~mm}) 36$ cases and Low-risk: L1 (<=4mm) 0, L2 (>4-6mm) 5, L3 (>6-8mm) 4 and L4 $(>8 \mathrm{~mm}) 3$ cases

89 patients completed standard follow-up and were discharged. Positive scans included Lung tumours (3) - (two underwent lobectomy); Aspergilloma (1); Rectal carcinoma (1)- discovered by nonFleischner abdominal CT. Surveillance was discontinued for: Patient choice/co-morbidity (8); Nodule resolution (3); Not documented/ lost (6).

Conclusion Fleischner guidelines were well adhered to and were also utilised where their application is less well defined e.g. development of a new nodule during follow-up prompted either re-initiation or more commonly continued/modified trajectory of Fleischner an area notably not well covered in current guidance. Furthermore principals of Fleischner recommendations were applied to multiple nodules but management of such patients is often not as easily followed as solitary nodules.

MacMahon et al, University of Chicago, Radiology 2005; 237:295-400. 


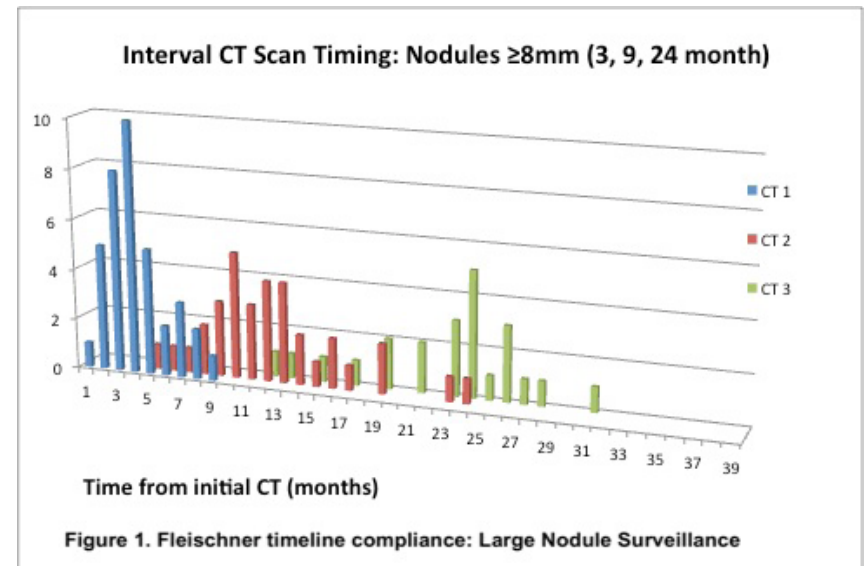

Abstract P195 Figure 1

\section{P196 PERCUTANEOUS ULTRASOUND-GUIDED BIOPSY OF INTRATHORACIC PARIETAL MASSES - A SAFE ALTERNATIVE TO CT-GUIDED BIOPSY?}

doi:10.1136/thoraxjnl-2012-202678.257

TRG Simpson, G Constantinescu, P Mellor, S Lohani, B Khan, M Mushtaq, I Abdelhadi, B Bhattacharjee, V Serafimov. Darent Valley Hospital, Dartford and Gravesham NHS Trust, Dartford, UK

Background The current gold standard method for sampling intrathoracic lesions is via a CT-guided approach. However, most parietal-attached intrathoracic lesions can be visualised with ultrasound and sampled.

Aims A prospective audit of consecutive patients with CT-identified intrathoracic parietal-attached lesions, sampled percutaneously by an ultrasound-guided approach, was carried out to assess efficacy and safety. The lung MDT was instrumental in selecting patients.

Materials and Methods Seventeen consecutive patients were audited over a span of 8 months. This cohort included 12 males and 5 females with an age range from 42 to 84 years (median 63 years). The biopsies were performed by 4 skilled investigators assisted by a specialist nurse, using an 18 gauge single-trochar puncture under standard aseptic conditions. A Toshiba Applio ultrasound unit, with Doppler-flow map capabilities was used to avoid vessel puncture. Patients recovered in the radiology department observation ward.

Results Interpretable specimens were obtained in 16 patients. A single patient needed a repeat, successful, US-guided procedure. The median duration for the procedure was 26 minutes, with a median observation time before discharge of a further 40 minutes. Two patients developed small pneumothoraces and one patient suffered minor haemoptysis, none of which required admission.

Conclusion Where applicable, this technique is safe, fast, avoids radiation and may result in fewer complications compared to the CTguided approach. Fewer personnel are required and CT scanner time is freed for other uses. Moreover, in the hands of an ultrasound-skilled respiratory physician, this method correctly applied would provide an earlier route to diagnosis for the Lung MDT.

\section{P197 OBTAINING A TISSUE DIAGNOSIS IN LUNG CANCER PATIENTS WITH POOR PERFORMANCE STATUS MAY NOT INFLUENCE TREATMENT OR CONFER SURVIVAL BENEFIT}

doi:10.1136/thoraxjnl-2012-202678.258

'JD Maclay, ${ }^{2} \mathrm{~J}$ Farley, ${ }^{1} \mathrm{C}$ Tweed, ${ }^{3} \mathrm{~J}$ van der Horst, ${ }^{4} \mathrm{~S}$ Bicknell, 'R Milroy. ${ }^{1}$ Glasgow Royal Infirmary \& Stobhill Hospital, Glasgow, UK; ${ }^{2}$ Stobhill Hospital, Glasgow, UK; ${ }^{3}$ Glasgow Royal Infirmary, Glasgow, UK; ${ }^{4}$ Gartnavel General Hospital, Glasgow, UK

Introduction Further investigation and treatment following a radiological diagnosis of lung cancer is influenced by the fitness of a patient. A pragmatic approach to investigative procedures is often adopted based on the risks and benefits. Another consideration is whether tissue diagnosis is necessary for anticipated future treatment. Tissue diagnosis is usually deemed essential prior to administration of radical radiotherapy and chemotherapy, but less so for palliative radiotherapy. Methods All patients with lung cancer diagnosed in North Glasgow in 2009 and 2010 were prospectively recorded in a registry. We subsequently investigated the relationships between WHO performance status (PS) and tissue diagnosis, treatment and survival. Patients were followed up for at least 18 months after entry into the registry. Results 1190 patients were diagnosed with lung cancer during the study period and clinical details were recorded at a multidisciplinary meeting. PS was recorded in $91 \%$.

Overall, tissue diagnosis was achieved in $76 \%$ of patients. Tissue diagnosis was achieved in $98 \%$ of patients with PS 0 following diagnostic procedure or surgery (table 1). Nearly $90 \%$ of these patients underwent chemotherapy, surgery or radical radiotherapy.

Tissue diagnosis was attempted in $71 \%$ and $46 \%$ of PS 3 and 4 respectively. Of these patients, treatment was influenced by tissue diagnosis in $15 \%$ and $0 \%$. Survival was compared in these patients and there was no difference between patients with a PS of 3 or 4 that had tissue diagnosis attempted and those that did not (median days (interquartile range); PS3: tissue 53 (19-138) vs no tissue 59 (17-156); PS4: 18 (8-36) vs 16 (6-32)).

Conclusions A significant percentage of patients with performance status 3 and 4 undergo diagnostic tests to establish a tissue diagnosis. However, treatment is only influenced by this in a minority of cases. Considering likely future treatment is important when pursuing a tissue diagnosis in these patients. In addition, attempting tissue diagnosis in these patients did not confer any survival benefit.

\section{P198 TEN YEAR FOLLOW UP OF MESOTHELIOMA IN NORTH YORKSHIRE}

doi:10.1136/thoraxjnl-2012-202678.259

R Smith, AK Datta. York Teaching Hospital, Hull York Medical School, York, UK

All 123 malignant mesothelioma patients in York and North Yorkshire between 2002-2011 were analysed from Cancer Registry and

Abstract P197 Table 1

\begin{tabular}{|c|c|c|c|c|c|c|}
\hline & 0 & 1 & 2 & 3 & 4 & Not recorded \\
\hline$n$ & 132 & 381 & 336 & 186 & 48 & 107 \\
\hline Tissue diagnosis attempted, $\mathrm{n}(\%)$ & $126(96)$ & $355(93)$ & $300(89)$ & $132(71)$ & $22(46)$ & $59(55)$ \\
\hline Tissue diagnosis achieved ${ }^{*}, \mathrm{n}(\%)$ & $129(98)$ & $358(94)$ & $278(83)$ & $118(63)$ & $17(35)$ & $55(51)$ \\
\hline \multicolumn{7}{|l|}{ Treatment, n (\%) } \\
\hline Best supportive care & $4(3)$ & $29(8)$ & $68(25)$ & $65(55)$ & $14(82)$ & $22(40)$ \\
\hline Palliative XRT & $11(9)$ & $82(23)$ & $91(33)$ & $36(31)$ & $3(18)$ & $17(31)$ \\
\hline Chemotherapy & $66(51)$ & $133(37)$ & $86(31)$ & $15(13)$ & $0(0)$ & $9(16)$ \\
\hline Surgery or radical XRT & $48(37)$ & $114(32)$ & $33(12)$ & $2(2)$ & $0(0)$ & $7(13)$ \\
\hline
\end{tabular}

*Some patients had tissue diagnosis following a surgical procedure. 